\title{
Successful Management of Facebook Addiction in Bangladesh: A Case Report
}

\section{Tanjir Rashid Soron*}

Cyberpsychology Research and Consultation Center, Dhaka, Bangladesh

\section{Introduction}

In the last decade, the use of social networking sites (SNSs) has grown exponentially all over the world. Boyd, Ellison \& Nicole described Social networking sites (SNS) as "web-based service" that allow individuals to construct a public or semi-public profile within a bounded system articulate a list of other users with whom they share a connection and view and traverse their list of connections and those made by others within the system. Among the various social networking sites, Facebook is the most the popular one. Statistics provided by Facebook revealed that as of March 2014, there were 1.28 billion active users on the site per month, and at least 802 million of these users logged into Facebook every day. Approximately $81.2 \%$ of Facebook active users were outside the United States and Canada. Facebook is the most popular site in Bangladesh.

Kuss and Griffiths estimated that between 55\% and $82 \%$ of teenagers and young adults use SNSs on a regular basis. The percentage has certainly increased in the recent years due to wide availability of internet and rapid development of smart phones. People are using social networking sites fortheir very private issue to political and social topics. People of all age are using the Social networking sites (SNSs). However, young adults, particularly teenagers tended to be unaware of just how much time they really spent on social networking sites, and its effect on their academic performance and social interaction [1,2]. The excessive use of social networking sites is becoming a matter of concern for the parents, teacher and policy makers. It has brought the discussions about social networking sites addiction. SNS addiction has been defined by La Rose et al. as a failure to regulate usage, which leads to negative personal outcomes. However the concept of addiction is not easy to define and the usage of the term addiction has been considered as controversial however, according to Widyanto and McMurran central to its definition is the dependence on a substance or activity. Sadock and Sadock defined addiction as the repeated and increased use of a substance, the deprivation of which gives rise to symptoms of distress and an irresistible urge to use the agent again and which lead also to physical and mental deteriotion. The definition no longer limited to substances it now also includes certain behaviors. A growing number of researchers accept the possibility that the use of online applications can become addictive; the concept is contentious [3-5]. Social Networking Sites addiction may be seen from a biopsychosocial perspective [5]. Just like substance-related addictions, SNS addiction incorporates the experience of the 'classic' addiction symptoms, namely mood modification (i.e. engagement in SNSs leads to a favorable change in emotional states), salience (i.e. behavioral, cognitive, and emotional preoccupation with the SNS usage), tolerance (i.e., ever increasing use of SNSs over time), withdrawal symptoms (i.e., experiencing unpleasant physical and emotional symptoms when SNS use is restricted or stopped), conflict (i.e., interpersonal and intrapsychic problems ensue because of SNS usage), and relapse (i.e., addicts quickly revert back in their excessive SNS usage after an abstinence period).

Addictive tendency is common in all social networking sites and it is more common among the Facebook user. There is a growing number of articles regarding problematic Facebook use including Facebook addiction. However there is no universal definition of Facebook addiction. Considering the definition of addiction and biopsychosocial perspective of behavioral addiction Facebook addiction can be defined as repeated and increased use of Facebook neglecting other activities (academic, occupational, familial and social), deprivation of it leading to distress and an urge to use Facebook in spite of having negative personal outcomes. Regarding the characteristics of Facebook addicts Harzadın, stated the Facebook addicts may have problems with their families and friends at work or school. The addict people may start going out less or spending less time out with friends due to the time they spend on Facebook. While they are in front of the computer, they may remain unresponsive to the things around them.

Balci and Gölcü'nün in their study among the Turkey students 5.1\% of the participants was addicted and $22.6 \%$ of them was risky users. Espinoza and Pezoa reported a case on Facebook addiction in Mexico [6-8].

Most of the articles published so far focused on the pattern, prevalence and impact of Facebook addiction. However, there is scanty of article regarding the management of Facebook addiction and there is no reported case of Facebook addiction in Bangladesh so far the knowledge of the author. In this article, I tried to report the first case of Facebook addiction in Bangladesh and its successful management. This case may help the psychiatrist of developing country like Bangladesh to consider assessing the Facebook use of the patients on their clinical setting. Many of them consider that the Facebook use related problem or Facebook addictionis uncommon in this region. Moreover, my experience on the successful management may help others to manage their clients of Facebook addiction. Hopefully this case will help to get the attention of psychiatrist and researchers to diagnose, manage and explore the Facebook addiction that is still a topic of debate.

\section{Case Report}

This report is about a case of 27 year unmarried man. He was brought in the outpatient department of Bangabandhu Sheikh Mujib Medical University by his 71 year old father with the complaints of using Facebook all day long. He was single and completed his graduation in 2013. He was an average student and third among his five siblings. He has been suffering some sort of speech difficulty since his childhood because of his stammering. There was no other developmental delay.

*Corresponding author: Tanjir Rashid Soron, Cyberpsychology Research and Consultation Center Dhaka, Bangladesh, Tel: 8801718827138; E-mail: tanjirsoron@yahoo.com

Received December 31, 2014; Accepted January 25, 2015; Published February 03, 2015

Citation: Soron TR (2015) Successful Management of Facebook Addiction in Bangladesh: A Case Report. J Psychiatry 18: 247 doi:

10.4172/2378-5756.1000247

Copyright: (C) 2015 Soron TR. This is an open-access article distributed under the terms of the Creative Commons Attribution License, which permits unrestricted use, distribution, and reproduction in any medium, provided the original author and source are credited 
He had a few friends. He was shy, introvert and less social. There were some neurotic traits in his personality. However, there was no history of substance use related disorder or any other prior mental illness and there was no history of mental illness in his family. This young man created his Facebook account in July 2013. He gathered 1170 Facebook friends by August 2014, $80 \%$ of them were female. His involvement in Facebook has increased day by day. He enjoyed giving comments on other posts and photos, chatting on friends, providing his own photos and post. Whenever anyone commented on his posts or photos he felt excited. He liked to use Facebook in closed door and used Facebook almost 18 hours per day and remained logged in all the time. His daily life centered on the activities of Facebook use. The man stopped going outside, refused to join any job or social functions. He was not interested to the real people around him even to his sick parents rather fantasized the virtual world of Facebook. The young man used to become irritable, tense and restless when any one disturbed him during Facebook use. Sometimes he was aggressive and verbal abusive towards the family members. He spent the whole night in Facebook, avoid breakfast and bathing even did not like to talk anyone. Initially he tried to stop or at least to reduce his Facebook use. However, the distress of logged out for few hours accelerated his attraction to Facebook. He was using Facebook continuously for about 36 hours just prior to his first visit to this institution. Being very anxious, the father brought him to the Psychiatry department.

During interview, I came to know that he created three Facebook accounts using fake names and email addresses. He became excited every time he watched people liked his "posts" or "photo". When other Facebook users mentioned him in their Facebook updates, he became enthusiastic and involved in more Facebook activities. The photos of his female Facebook friends were one of his main attractions of the Facebook. However he was not very interested in chatting in Facebook or playing games in here. The physical examination revealed no abnormality. He was looking at his Facebook notification often through his smart phone during the interview. His mental state examination revealed that his mood was euthymic, rapport was established and maintained, there was no oddity of social and motor behavior. He was stammering occasionally. There was no formal thought disorder and no hallucination or delusion. He agreed that he had some problem due to Facebook and need help. I used Facebook addiction Scale (Bangla) to assess his severity addiction. I developed the scale by reorganizing the Young Internet addiction Scale with the kind permission of Dr. Kimberly Young and used it in one of my previous study in 2012 where we considered a score more than 60 is addictive. However, the article is yet to be published. He scored 86 in this 20 -item Likert type scale where 100 indicate maximum severity of addiction.

We made an agreed plan to overcome this situation and to reduce the duration of use to an acceptable limit using Cognitive behavioral therapy (CBT). I gave him Cognitive Behavior Therapy for Facebook addiction that was inspired by the Cognitive Behavior Therapy for Internet Addiction developed by Kimberly Young [9].

At first he was requested to make a daily Facebook use record book that was useful to evaluate his Facebook related behavior and to establish a baseline for treatment. Based on the results of his daily log, I reviewed how many hours per week he spent on Facebook in every session. He was encouraged to take routine Facebook log out schedule and to go see what a family member is doing in the next room. Using cognitive restructuring clients helped him to reevaluate how rational and valid to use Facebook all day long leaving all other activities and neglecting people of real life for the virtual people. To help him, I advised the family to celebrate an internet free family day every week. It may be considered as a modified digital detoxification program. I gave him 6 session of Cognitive Behavior Therapy for Facebook addiction without any other pharmacological intervention. Each session was consisted of about 40 minutes. He also participated in a social skilltraining program. I treated him in the outpatient department and he improved with the cooperation of his family members. He deleted his two fake Facebook accounts and reduced his duration of Facebook use less than 1 hour after the treatment. He was planning to join a new job shortly.

Inform written consent was taken from the patient to report his case anonymously and appropriate ethical measures were taken to ensure confidentiality.

\section{Discussion}

The Internet addiction disorder is not listed in the latest DSM manual (DSM-5, 2013), Gambling disorder is the only behavioral (non-substance related) addiction included in DSM-5. However internet gaming disorder is listed in an appendix as a disorder requiring further study. Regarding Facebook addiction there is no concise and concrete diagnosis criteria yet. I made the diagnosis depending on similarity of Facebook addiction with internet addiction and behavioral addiction. It also had the core feature of addiction like development of tolerances, withdrawals, using in spite of having negative consequences etc. Though there is no reported case of Facebook addiction in the developing country like Bangladesh we definitely are facing some sorts of problem due to excessive use of Facebook in our lives with its blessings. There were some arguments that the social networking sites use related problem was limited to the Western and developed world. This article provided the evidence that it had crossed the boundaries of western developed countries and it had emerged as a new mental health problem for third world developing countries.

He was shy, introvert and had low self-esteem. Orr et al. reported that shy people spend large amounts of time on Facebook and have large amounts of friends on this SNS. I was interested to report the case as it focused on an upcoming mental health problem and its successful recovery of our modern life. However it is still too early to make everyone believe the existence of Facebook addiction [10-17].

\section{Acknowledgement}

I am grateful to the patient for his kind consent to allow me to report. I am also grateful to the faculty members and colleagues' of department of Psychiatry of Bangabandhu Sheikh Mujib Medical University for their encouragement to manage the patient.

\section{References}

1. Kuss DJ, Griffiths MD (2011) Online social networking and addiction: A review of the psychological literature. Int J Environ Res Public Health 8: 3528-3552.

2. Meena PS, Mittal PK, Solanki RK (2012) Problematic use of social networking sites among urban school going teenagers. Industrial Psychiatry Journal 21(2): 94-97.

3. LaRose R, Kim J, Peng W (2010) Social networking: Addictive, compulsive problematic, or just another media habit? In: Z. Papacharissi, editor. A networked self: Identity, community, and culture on social network sites. NY: Taylor \& Francis, New York

4. Widyanto L, McMurran M (2004) The Psychometric properties of the internet addiction test. Cyberpsychol Behav 7: 443-450.

5. Griffiths MD (2005) A "components" model of addiction within a biopsychosocia framework. J Subst Use 10: 191-197.

6. Harzadın T (2012) Facebook Addiction among high school students in Turkey 
Citation: Soron TR (2015) Successful Management of Facebook Addiction in Bangladesh: A Case Report. J Psychiatry 18: 247 doi: 10.4172/2378-5756.1000247

Page 3 of 3

7. Balci Ş, Gölcü A (2013) Facebook Addiction among University Students In Turkey: "Selcuk University Example". Journal of Studies in Turkology 34: 255-278.

8. Espinoza I, Pezoa R (2013) Facebook addiction in mexico: a case report. European Psychiatry 28: 1.

9. Young KS (2011) CBT-IA: The First Treatment Model for Internet Addiction. Journal of Cognitive Psychotherapy. 25: 304-312.

10. Orr ES, Ross C, Simmering MG, Arseneault JM, Orr RR (2009) The influence of shyness on the use of Facebook in an undergraduate sample. CyberPsychol Behav 12: 337-340.

11. Andreassen CS, Torsheim T. Brunborg GS, Pallesen S (2012) Development of a Facebook Addiction Scale. Psychol Rep 110: 501-517.

12. American Psychiatric Association (2013). Diagnostic and Statistical Manual of
Mental Disorders ( $5^{\text {th }}$ edn). Arlington, VA: American Psychiatric Publishing 797-798.

13. Benjamin J Sadock, Virginia A Sadock (2005) Kaplan and Sadock's Pocket Handbook of Clinical Psychiatry $\left(4^{\text {th }} \mathrm{edn}\right)$, Lippincott Williams and wilkins, Philadelphia USA

14. Boyd DM, Ellison, Nicole B. (2007). Social network sites: Definition, history, and scholarship. J Comput Mediat Commun 13: 11-14.

15. Ferraro G, Caci B, D'Amico A, Di Blasi M (2007) Internet Addiction Disorder: An Italian Study, Cyberpsychol Behav 10: 170-175.

16. Facebook Company info: Facebook newsroom.news-room.fb.com (2014)

17. Hur MH (2006) Demographic, Habitual, and Socioeconomic Determinants of Internet Addiction Disorder: An Empirical Study of Korean Teenagers. Cyberpsychol Behav 9: 514-525. 